\title{
A different surgical technique for cardioverter defibrillator implantation in pediatric patients: Pericardial-pleural pocket
}

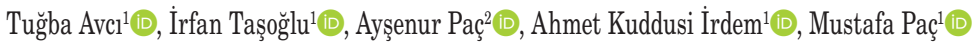 \\ ${ }^{1}$ Department of Cardiovascular Surgery, Türkiye Yüksek İhtisas Training and Research Hospital, Ankara, Turkey \\ ${ }^{2}$ Department of Pediatric Cardiology, Türkiye Yüksek İhtisas Training and Research Hospital, Ankara, Turkey \\ Received: September 08, 2016 Accepted: August 29, 2018 Published online: April 24, 2019
}

\section{ABSTRACT}

There is no particular method for the use of implantable cardioverter defibrillators (ICDs) in the pediatric population. Herein, we present our new technique applied in three pediatric patients.

Keywords: Congenital arrhythmia; implantable cardioverter defibrillator; surgical implantation.

There is no particular method for the use of implantable cardioverter defibrillators (ICDs) in the pediatric population. To date, many techniques have been described by several authors. ${ }^{[1-3]}$ Herein, we present our new technique applied in three pediatric patients.

\section{HOW TO DO IT?}

Of three patients who needed ICD implantation, the first was a four-year-old with a ventricular septal defect (VSD) and Brugada syndrome, and the other patients were one and six years old with prolonged QT syndrome, respectively. A written informed consent was obtained from the parents of each patient.

The VSD closure via sternotomy was carried out in the first patient, followed by ICD implantation. In the other two patients, ICD implantation was done via a left thoracotomy through the fourth intercostal space. The ICD system was implanted subcutaneously in the right lower quadrant of the abdomen. A defibrillator lead was tunneled from the abdomen to the left thorax. A pericardial pocket was created with an autologous pericardium on the pleural surface of the pericardium to the planar projection of the left posterior segment of the heart (Figures 1, 2, and 3). The leads were, then, placed in this pocket in a loop shaped fashion (Figure 4). Sensing, pacing, and defibrillation threshold (DFTs) impedances were verified intraoperatively. The optimal configurations of the leads were found by checking the impedances.
Sensing and pacing leads were, then, sutured to the anterior wall of the right ventricle.

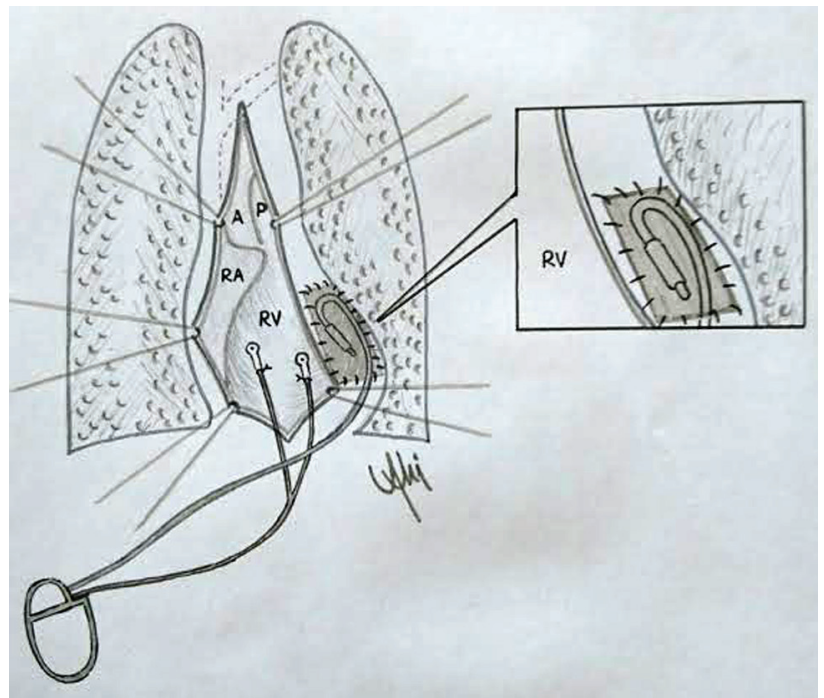

Figure 1. Illustration of the implantable cardioverter defibrillator implantation technique.

Corresponding author: Tuğba Avc1, MD. Türkiye Yüksek İhtisas Eğitim ve Araştırma Hastanesi Kalp ve Damar Cerrahisi Kliniği, 06230 Altındağ, Ankara, Turkey. Tel: +90 505 - 4402428 e-mail: dr.tugbadonmez@gmail.com

\section{Citation:}

Avcı T, Taşoğlu İ, Paç A, İrdem AK, Paç M. A different surgical technique for cardioverter defibrillator implantation in pediatric patients: Pericardial-pleural pocket. Cardiovasc Surg Int 2017;4(2):36-38. 


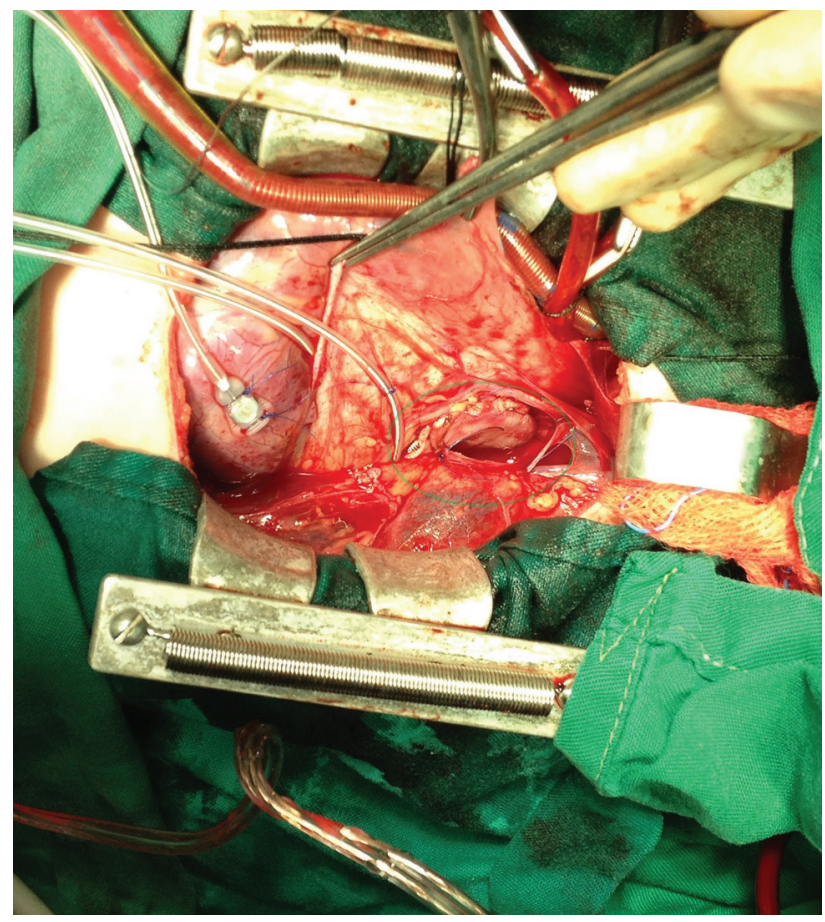

Figure 2. Intraoperative view of the heart and leads.

Sensing, pacing, DFTs, and impedances were intraoperatively verified and evaluated at one, three, and six months, respectively. At one year of follow-up of the first patient, there was no deformation in the leads, sensing, pacing, and DFTs (Figure 4). At 14 and 18 months of follow-up of the other two patients, respectively, there were no procedure-related complications. We believe that the pericardial gap can

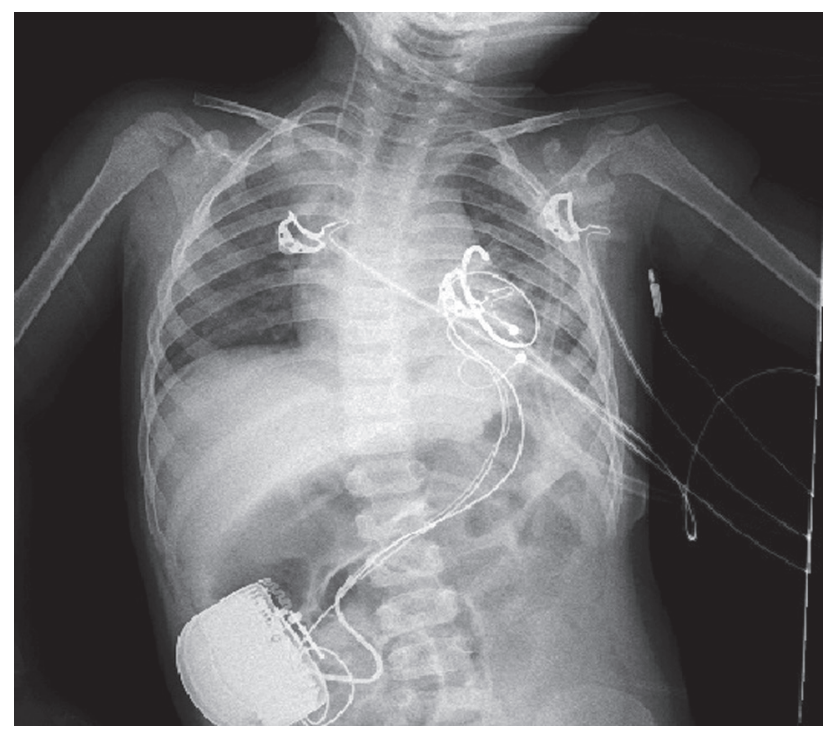

Figure 3. Postoperative chest and abdomen X-ray.

avoid adhesion of the lung and myocardium to the ICD system.

Currently, ICDs have been widely used in children to prevent sudden cardiac death caused by various pathologies. However, a standard implantation technique for children, particularly for infants, has not been established, yet. ${ }^{[2]}$ Transvenous lead placement is not possible for infants and young children due to the presence of small vessel diameters. Therefore, epicardial, subcutaneous, and pericardial ICD implantations should be considered. On the other hand, many of these systems are associated with

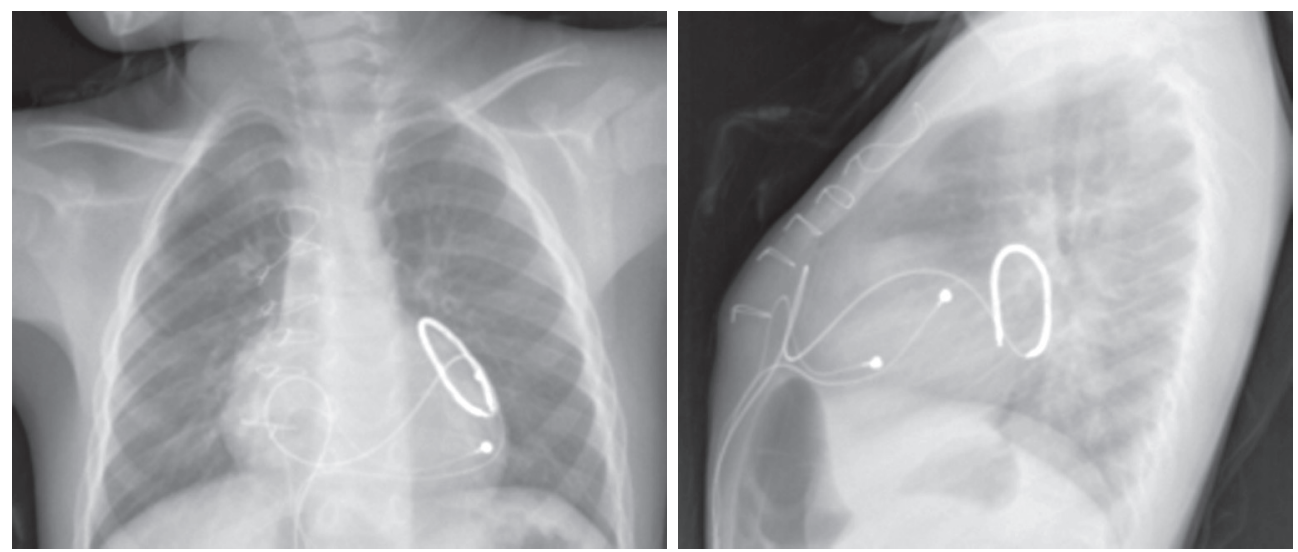

Figure 4. Postoperative third month anteroposterior and left lateral X-ray. 
high rates of late complications. In the literature, lead fractures, insulation breakage, migration or buckling of the patch lead and constrictive pericarditis have been reported as the most common lead-related complications. ${ }^{[4,5]}$ We believe that our new technique may decrease complication rates, since the pericardial pocket is a barrier against the adhesions. By avoiding adhesions, positional deformities can be also prevented.

In conclusion, there are many implantable cardioverter defibrillator implantation techniques; however, clinical experiences will show which technique is the most effective and long-lasting.

\section{Declaration of conflicting interests}

The authors declared no conflicts of interest with respect to the authorship and/or publication of this article.

\section{Funding}

The authors received no financial support for the research and/or authorship of this article.

\section{REFERENCES}

1. Kriebel T, Ruschewski W, Gonzalez y Gonzalez M, Walter K, Kroll J, Kampmann C, et al. ICD Implantation in infants and small children: the extracardiac technique. Pacing Clin Electrophysiol 2006;29:1319-25

2. Suzuki S, Motohashi S, Matsumoto M. Surgical techniques for implanting implantable cardioverter defibrillators in children and infants. Surg Today 2014;44:1801-6.

3. Bové T, François K, De Caluwe W, Suys B, De Wolf D. Effective cardioverter defibrillator implantation in children without thoracotomy: a valid alternative. Ann Thorac Surg 2010;89:1307-9.

4. Korte T, Jung W, Spehl S, Wolpert C, Moosdorf R, Manz $\mathrm{M}$, et al. Incidence of ICD lead related complications during long-term follow-up: comparison of epicardial and endocardial electrode systems. Pacing Clin Electrophysiol 1995;18:2053-61.

5. Chevalier P, Moncada E, Canu G, Claudel JP, Bellon C, Kirkorian G, et al. Symptomatic pericardial disease associated with patch electrodes of the automatic implantable cardioverter defibrillator: an underestimated complication? Pacing Clin Electrophysiol 1996;19:2150-2. 